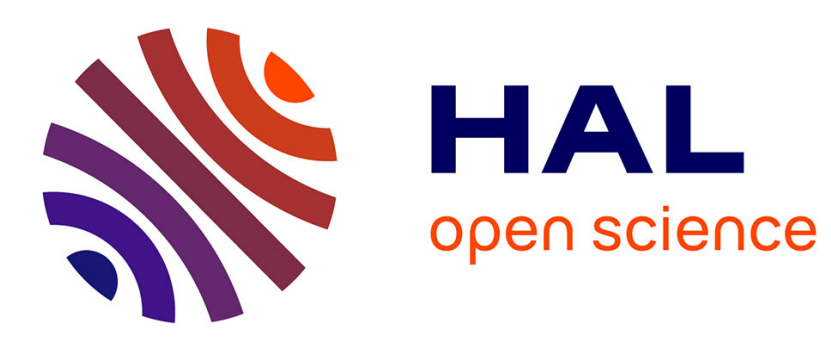

\title{
Nanoscale mechanism of rare-earth doping in Ga-codoped glassy As-Sb selenides
}

\author{
Yaroslav Shpotyuk
}

\section{To cite this version:}

Yaroslav Shpotyuk. Nanoscale mechanism of rare-earth doping in Ga-codoped glassy As-Sb selenides. Journal of the American Ceramic Society, 2017, 100 (9), pp.3865-3874. 10.1111/jace.14909 . hal01614772

HAL Id: hal-01614772

\section{https://hal-univ-rennes1.archives-ouvertes.fr/hal-01614772}

Submitted on 16 May 2018

HAL is a multi-disciplinary open access archive for the deposit and dissemination of scientific research documents, whether they are published or not. The documents may come from teaching and research institutions in France or abroad, or from public or private research centers.
L'archive ouverte pluridisciplinaire HAL, est destinée au dépôt et à la diffusion de documents scientifiques de niveau recherche, publiés ou non, émanant des établissements d'enseignement et de recherche français ou étrangers, des laboratoires publics ou privés. 
DR. YA. SHPOTYUK (Orcid ID : 0000-0001-6710-7839)

Article type : Article

Editor: Prof. Pierre Lucas

\title{
Nanoscale mechanism of rare-earth doping in Ga-codoped glassy As-Sb selenides
}

\author{
Yaroslav Shpotyuk ${ }^{1-3, *}$ \\ ${ }^{1}$ Centre for Innovation and Transfer of Natural Sciences and Engineering Knowledge, \\ Faculty of Mathematics and Natural Sciences, University of Rzeszow, 1, Pigonia str., 35-959 \\ Rzeszow, Poland \\ ${ }^{2}$ Department of Sensor and Semiconductor Electronics, Ivan Franko National University of \\ Lviv, \\ 107, Tarnavskogo str., 79017, Lviv, Ukraine \\ ${ }^{3}$ Laboratoire Verres et Céramiques, UMR-CNRS 6226, Université de Rennes 1, \\ 35042 Rennes Cedex, France \\ *The corresponding author e-mail: yashpotyuk@gmail.com
}

\begin{abstract}
The method of annihilating positrons in positron annihilation lifetime measuring mode is applied to study mechanism of rare-earth doping in Ga-codoped arsenic selenide $\mathrm{As}_{2} \mathrm{Se}_{3}$ glass modified with $\mathrm{Sb}$. The atomic-deficient structure of parent $\mathrm{As}_{2} \mathrm{Se}_{3}$ glass is imagined as containing positron trapping sites in the form of free-volume voids within cycle-type arrangement of corner-sharing trigonal $\mathrm{AsSe}_{3 / 2}$ pyramids, composed of atomic-accessible geometrical holes arrested by surrounding atomic-inaccessible Se-based bond-free solid angles. The Ga-codoping in $\mathrm{As}_{2} \mathrm{Se}_{3}$ glass causes gradual decrease in trapping rate and fraction of trapped positrons due to agglomeration of free-volume voids. Partial As-to-Sb replacement in Ga-codoped As-Se glasses leads to better stability against crystallization processes and
\end{abstract}


possibility to further rare-earth doping without principal changes in the type of positron trapping defects. Effect of 500 wppm of $\operatorname{Pr}^{3+}$ in $\mathrm{Ga}_{2}\left(\mathrm{As}_{0.28} \mathrm{Sb}_{0.12} \mathrm{Se}_{0.60}\right)_{98}$ glass is explained in terms of competitive contribution of changed occupancy sites in Ga-modified glassy network available for rare-earth ions and annihilating positrons.

Keywords: nanoscale, rare-earth ions, chalcogenide glasses; nanoinhomogeneities, positrons.

\section{Introduction}

Rare-earth (RE) doped chalcogenide glasses $(\mathrm{ChG})$ attract great attention in modern materials science community as versatile device media for a variety of active applications in mid-IR optics including fiber-optics amplifiers and IR lasers. ${ }^{1,2,3}$ However, this sphere of chalcogenide photonics has still being highly disputable now because of insufficient knowledge on the nature of RE-activated functionality in covalent-saturated ChG networks.

To be functioning, the RE atoms should occupy an electrically active " +3 " state, which is principally impossible for typical ChG matrices under a condition of global electroneutrality proper to full saturation of covalent bonding in respect to the known Mott's 8 - $N$ rule. ${ }^{4,5}$ Local structural nanoinhomogeneities possessing an effective negative electrical charge are crucially desirable to compensate positive electrical charge of RE ions embedded in covalentlinked glassy skeleton. This problem can be resolved extrinsically due to some chemical modifiers such as Ga or In added to ChG in small amounts, which don't disturb their glass-

forming ability. ${ }^{6-10}$ Preliminary $\mathrm{ChG}$ doping with these elements (which therefore can be conditionally defined as Ga- or In-codoping) seems most efficient way to stabilize randomlydistributed sites in ChG matrix possessing local excess of uncompensated negative electrical 
charge along with unoccupied atomic-accessible space (named as free-volume holes) needed to reside the electrically-active RE dopants without any clustering.

With this in mind, the present problem of RE-activated $\mathrm{ChG}$ functionality could be reexamined at a nanoscale as returning to known filling-space controversy in a host-guest chemistry. ${ }^{11,12}$ Successful RE-doping is relied on such nanospace-tailoring technology, when some rigid chemical bonding arrangement is destructed in a host glassy network at a preliminary stage of $\mathrm{Ga} / \mathrm{In}$-codoping to create appropriate sites available for occupation by guest RE ions at a further stage of RE-doping.

In this work, the method of annihilating positrons in positron annihilation lifetime (PAL) measuring mode, which is known to be advanced instrumentation tool efficiently exploring nanospace at atomistic and sub-atomistic length-scales, ${ }^{13-18}$ will be applied to study the mechanism of RE-doping (by $\mathrm{Pr}^{3+}$ ions) in Ga-codoped arsenic-antimony selenide $(\mathrm{As} / \mathrm{Sb})_{2} \mathrm{Se}_{3} \mathrm{ChG}$.

\section{Experimental}

\section{(1) ChG preparation and input characterization}

In this work, the ChG probes within $\mathrm{Ga}_{\mathrm{x}}\left[(\mathrm{As} / \mathrm{Sb})_{0.40} \mathrm{Se}_{0.60}\right]_{100-\mathrm{x}}$ cut-section will be examined in a row of subsequent steps from (1) stoichiometric glassy arsenic selenide $\mathrm{g}-\mathrm{As}_{2} \mathrm{Se}_{3}$, serving as starting point, then to (2) Ga-codoped $\mathrm{g}-\mathrm{As}_{2} \mathrm{Se}_{3}$ of optimal $\mathrm{g}-\mathrm{Ga}_{2}\left(\mathrm{As}_{0.40} \mathrm{Se}_{0.60}\right)_{98}$ composition, further to (3) optimal Ga-codoped As-Sb selenide g-Ga $\left(\mathrm{As}_{0.28} \mathrm{Sb}_{0.12} \mathrm{Se}_{0.60}\right)_{98}$, and finally to (4) g-Ga $\left(\mathrm{As}_{0.28} \mathrm{Sb}_{0.12} \mathrm{Se}_{0.60}\right)_{98}$ doped with $500 \mathrm{wppm}$ of $\operatorname{Pr}^{3+}$.

These ChG were prepared from high-purity elemental precursors, e.g. Ga (7N), As (5N), Se $(5 N)$, and $\operatorname{Pr}_{2} \mathrm{Se}_{3}(3 \mathrm{~N})$, the ingredients being specially purified by distillation with low 
evaporation rate to remove impurities $\left(\mathrm{O}, \mathrm{C}, \mathrm{H}_{2} \mathrm{O}\right.$, and $\left.\mathrm{SiO}_{2}\right)$. Appropriate amounts of ingredients with total weight close to $30 \mathrm{~g}$ were put into silica tube of $10 \mathrm{~mm}$ diameter. Then, the ampoules were sealed under a vacuum, heated up to $900{ }^{\circ} \mathrm{C}$ with $2{ }^{\circ} \mathrm{C} / \mathrm{min}$ rate and stayed at this temperature for $10 \mathrm{~h}$ in a rocking furnace with further quenching into water from 700 ${ }^{\circ} \mathrm{C}$. To remove mechanical strains appeared during rapid quenching, the alloys were annealed during $6 \mathrm{~h}$ at temperature of $10{ }^{\circ} \mathrm{C}$ less than glass transition. Then, the obtained rods were cut into $\sim 2 \mathrm{~mm}$ disks and polished. A more detailed description of the $\mathrm{ChG}$ preparation procedure can find elsewhere. ${ }^{19-21}$

With respect to eventual using of RE-doped ChG in fiber optics, ${ }^{1,2}$ the thermal behavior of each sample was examined using differential scanning calorimetry (DSC) with TA Instruments Q20 (TA Instruments, Inc., New Castle, DE, USA). Typically, $10 \mathrm{mg}$ bulk samples were sealed in standard aluminum pans and heated at $10{ }^{\circ} \mathrm{C} / \mathrm{min}$ heating rate. The glass transition $\left(T_{g}\right)$ and crystallization $\left(T_{x}\right)$ temperatures were taken as onset points at the endothermic heat flow peaks with a resulting accuracy no worse than $\pm 2{ }^{\circ} \mathrm{C}$. To be suitable candidate for fiber drawing, the $\mathrm{ChG}$ should be stable against crystallization. The stability of $\mathrm{ChG}$ on reheating above $T_{g}$ can be estimated by the Hruby parameter determined as $\Delta T=\left(T_{x}-T_{g}\right)$ difference also known as glass stability factor. ${ }^{22}$ Typically, this $\Delta T$ value should be higher than $100{ }^{\circ} \mathrm{C}$, which is assumed to be sufficient for successful fiber drawing.

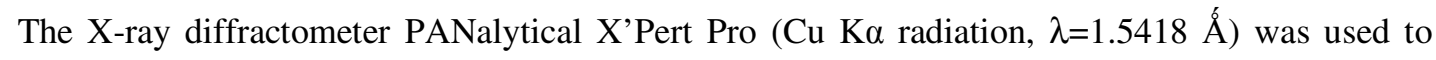
check an amorphous nature of the prepared alloys. The X-ray diffraction (XRD) patterns of bulk ChG samples were collected in reflection mode at room temperature in the $2 \theta$ range from 5 to $90^{\circ}$.

The densities $\rho$ of polished disk samples were measured using the Archimedes displacement method with Mettler Toledo analytical balances operated at room temperature 
using ethanol. The mean value of three tests was taken for each sample as final density $\rho$, the accuracy being $\pm 0.005 \mathrm{~g} \cdot \mathrm{cm}^{-3}$. The molar volumes $V_{m}$ of the $\mathrm{ChG}$ samples were calculated at the basis of measured densities $\rho$ as:

$$
V_{m}=\frac{\sum_{i=1}^{N} x_{i} M_{i}}{\rho},
$$

where $M_{i}$ and $x_{i}$ were the molar weight and percentage of each element in the compound, respectively.

\section{(2) Optical characterization}

The optical transmission spectra of the samples in the range of $0.8-2.5 \mu \mathrm{m}$ were registered using UV/Vis/NIR spectrophotometer PerkinElmer LAMBDA 950 operating with $2 \mathrm{~nm}$ resolution, while IR transmission spectra in the range of $1.5-25 \mu \mathrm{m}$ were measured using Bruker Tensor 37 spectrometer with $2 \mathrm{~cm}^{-1}$ resolution. The fluorescence emission in the range of 850-1400 nm was recorded using Fluorolog-3 (Horiba) spectrometer equipped with PMT detector. The $450 \mathrm{~W}$ Xenon lamp eliminating in $500-800 \mathrm{~nm}$ range was used for excitation, and special cuvette was employed to perform low-temperature fluorescence measurements under liquid nitrogen $(77 \mathrm{~K})$.

\section{(3) Positron annihilation studies}

The PAL spectroscopy was employed first to trace the evolution of atomic-deficient freevolume structure of $\mathrm{As}_{2} \mathrm{Se}_{3}$-based $\mathrm{ChG}$, affected in subsequent steps of Ga-codoping and REdoping. 
The PAL measurements were performed using a fast-fast coincidence system of $230 \mathrm{ps}$ resolution based on two Photonis XP2020/Q photomultiplier tubes coupled to $\mathrm{BaF}_{2}$ scintillator 25.4A10/2M-Q-BaF-X-N detectors (Scionix, Bunnik, Holland) and ORTEC ${ }^{\circledR}$ electronics (ORTEC, Oak Ridge, TN, USA). The reliable PAL spectra were detected in a normal-measurement statistics ( $\sim 1 \mathrm{M}$ coincidences) under stabilized temperature $\left(22{ }^{\circ} \mathrm{C}\right)$ and relative humidity (35\%). The channel width of $6.15 \mathrm{ps}$ allows a total number of channels to be 8000 . The radioactive ${ }^{22} \mathrm{Na}$ isotope of relatively low $\sim 50 \mathrm{kBq}$ activity prepared from aqueous solution of ${ }^{22} \mathrm{NaCl}$ wrapped by Kapton ${ }^{\circledR}$ foil (DuPont ${ }^{\mathrm{TM}}$, Circleville, OH, USA) of $12 \mu \mathrm{m}$ thickness was used as positron source sandwiched between two identical tested samples.

The raw PAL spectra were processed with LT 9.0 program. $^{23}$ Under unchanged contribution from a source (with 372 ps and $\sim 2$ ns inputs), these spectra were decomposed into two normalized components with $\tau_{1,2}$ lifetimes and $I_{1,2}$ intensities $\left(I_{1}+I_{2}=1\right)$. Under above spectrometer resolution, this allows an error-bar for such arranged measuring protocol not worse than $\pm 0.005 \mathrm{~ns}$ in lifetimes and \pm 0.01 in intensities. Introducing third component in the envelope of fitting curves did not improve goodness of fitting significantly (the bound positron-electron states were not proper for studied ChG in full agreement with previous results. $^{24-26}$

\section{(4) Positron trapping parameterization under two-state singe-defect model}

Assuming that $\mathrm{x} 2$-term reconstructed PAL spectrum represents positron trapping in one kind of defects (i.e. the positrons of $n_{b}(t)$ concentration annihilating from defect-free bulk state with $\lambda_{b}$ rate, and the positrons of $n_{d}(t)$ concentration annihilating from defect-related state with $\lambda_{d}$ rate being previously trapped by these defects with $\kappa_{d}$ rate), and neglecting 
competitive detrapping escape of positrons from defect state, the simplest set of kinetics equations can be written as (Fig. 1): ${ }^{13-18}$

$$
\begin{aligned}
& \frac{d n_{b}(t)}{d t}=-\left(\lambda_{b}+\kappa_{d}\right) n_{b}(t), \\
& \frac{d n_{d}(t)}{d t}=-\lambda_{d} n_{d}(t)+\kappa_{d} n_{b}(t),
\end{aligned}
$$

where $n_{b}(t)$ and $n_{d}(t)$ are positron concentrations in bulk defect-free and defect states, respectively.

The full solution of the above set of eqs. under initial conditions $n_{b}(0)=1$ and $n_{d}(0)=0$ gives a normalized sum of negative exponentials with $\tau_{1,2}$ lifetimes and $I_{1,2}$ intensities (which are, in fact, the fitting parameters for experimentally measured raw PAL spectrum), where the longer lifetime $\tau_{2}$ is the lifetime specific to the vacancy-type defect $\tau_{d}\left(\tau_{2}=\tau_{d}\right)$, while the shorter lifetime $\tau_{l}$ is the "reduced bulk lifetime" (shorter in comparison with bulk nontrapped positron lifetime $\tau_{b}$ ). The center of mass of the PAL spectrum coincides with average positron lifetime $\tau_{a v}$ defined through normalized fractions of positron annihilations at defectfree bulk $\eta_{b}=\lambda_{b} \cdot\left(\lambda_{b}+\kappa_{d}\right)^{-1}$ and defect-specific $\eta_{d}=\kappa_{d} \cdot\left(\lambda_{b}+\kappa_{d}\right)^{-1}=\tau_{1} \cdot \kappa_{d}$ states $\left(I_{1}+I_{2}=\eta_{b}+\eta_{d}=1\right)$ :

$$
\tau_{a v}=I_{1} \tau_{1}+I_{2} \tau_{2}=\eta_{b} \tau_{b}+\eta_{d} \tau_{d}
$$

Other physical quantities (the positron trapping modes), in part, the defect-free bulk positron lifetime $\tau_{b}$ and trapping rate in defects $\kappa_{d}$ can be calculated from x2-term parameterized PAL spectra:

$$
\begin{aligned}
& \tau_{b}=\tau_{B}=\frac{1}{\lambda_{b}}=\frac{\tau_{1} \tau_{2}}{I_{1} \tau_{2}+I_{2} \tau_{1}}, \\
& \kappa_{d}=I_{2}\left(\frac{1}{\tau_{1}}-\frac{1}{\tau_{2}}\right)=\frac{I_{2}}{I_{1}}\left(\frac{1}{\tau_{b}}-\frac{1}{\tau_{d}}\right) .
\end{aligned}
$$

In addition, the $\left(\tau_{2}-\tau_{b}\right)$ difference can be accepted as a size measure for extended freevolume defects where positrons are trapped, as well as the $\tau_{2} / \tau_{b}$ ratio can be taken as direct 
signature of nature of these trapping defects in terms of equivalent number of monovacancies. $^{13}$

\section{Results and discussion}

\section{(1) Input and optical examination of RE-doping in As-Sb selenide ChG}

Input characteristics of the prepared $\mathrm{ChG}$ are gathered in Table 1.

It is known that partial As-by-Sb replacement within $\mathrm{Ga}_{\mathrm{y}}\left(\mathrm{As}_{0.40-\mathrm{x}} \mathrm{Sb}_{\mathrm{x}} \mathrm{Se}_{0.60}\right)_{100-\mathrm{y}}$ cut-section reveals a stabilizing effect on ChG network suppressing parasitic crystallization processes caused by Ga addition. ${ }^{27,28}$ That is why the Sb-modified $\mathrm{As}_{2} \mathrm{Se}_{3}$-based $\mathrm{ChG}$ will be examined, i.e. Ga-codoped arsenic selenide g- $\mathrm{Ga}_{2}\left(\mathrm{As}_{0.28} \mathrm{Sb}_{0.12} \mathrm{Se}_{0.60}\right)_{98}$ and $\mathrm{g}-\mathrm{Ga}_{2}\left(\mathrm{As}_{0.28} \mathrm{Sb}_{0.12} \mathrm{Se}_{0.60}\right)_{98}$ doped with 500 wppm of $\operatorname{Pr}^{3+}$.

As expected, the $\mathrm{Sb}$ addition causes increase in the $\mathrm{ChG}$ density $\rho$ due to heavier atomic mass of $\mathrm{Sb}$ in comparison with As. The same tendency is observed for molar volume $V_{m}$ showing lower atomic packing in Sb-contained ChG. No essential difference in both parameters is detected for RE-doped $\mathrm{g}-\mathrm{Ga}_{2}\left(\mathrm{As}_{0.28} \mathrm{Sb}_{0.12} \mathrm{Se}_{0.60}\right)_{98}$. All samples under research remain in vitreous state, as it follows from character amorphous halos observed on XRD patterns centered near $2 \theta=16^{\circ}, 30^{\circ}$ and $55^{\circ}$. The glass stability factor $\Delta T=\left(T_{x}-T_{g}\right)$ defined from DSC measurements is reliably higher than $100{ }^{\circ} \mathrm{C}$ for $\mathrm{g}-\mathrm{Ga}_{2}\left(\mathrm{As}_{0.28} \mathrm{Sb}_{0.12} \mathrm{Se}_{0.60}\right)_{98}$ doped with 500 wppm of $\mathrm{Pr}^{3+}$, which serves as an indication that this glass is suitable for technological routes exploring re-heating procedures (like glass molding or fiber drawing).

Optical transmission and absorption cross-section spectra in Vis-NIR 800-2500 nm range for $\mathrm{g}-\mathrm{Ga}_{2}\left(\mathrm{As}_{0.28} \mathrm{Sb}_{0.12} \mathrm{Se}_{0.60}\right)_{98}$ and $\mathrm{g}-\mathrm{Ga}_{2}\left(\mathrm{As}_{0.28} \mathrm{Sb}_{0.12} \mathrm{Se}_{0.60}\right)_{98}$ doped with 500 wppm of $\mathrm{Pr}^{3+}$ are shown in Fig. 2. In comparison to pure $\mathrm{g}-\mathrm{As}_{2} \mathrm{Se}_{3}$ or $\mathrm{g}-\mathrm{Ga}_{2}\left(\mathrm{As}_{0.40} \mathrm{Se}_{0.60}\right)_{98},{ }^{21}$ the $\mathrm{Sb}$ addition demonstrates a tendency to lower saturation level of optical transmittance due to increase in the refractive indices, since the electronic cloud of $\mathrm{Sb}$ is larger than that of As. ${ }^{29}$ In addition, 
the long-wave shift of optical absorption edge is observed with Sb adding, owing to its higher metallic behavior in respect to As, which decreases the optical band gap of ChG. No considerable changes are observed in optical transmission spectroscopy of un-doped and REdoped $\mathrm{g}-\mathrm{Ga}_{2}\left(\mathrm{As}_{0.28} \mathrm{Sb}_{0.12} \mathrm{Se}_{0.60}\right)_{98}$, apart from appearance of $\mathrm{Pr}^{3+}$-related absorption bands in the latter. Four absorption bands of $\operatorname{Pr}^{3+}$ are observed in the near-IR transmission region of doped ChG (see Fig. 2), these corresponding to inner-shell electron transitions of $\operatorname{Pr}^{3+}$ ions from the ${ }^{3} \mathrm{H}_{4}$ ground energy level to higher ones, in part ${ }^{3} \mathrm{~F}_{4}(\sim 1500 \mathrm{~nm}),{ }^{3} \mathrm{~F}_{3}(\sim 1600 \mathrm{~nm}),{ }^{3} \mathrm{~F}_{2}$ $(\sim 2050 \mathrm{~nm})$ and ${ }^{3} \mathrm{H}_{6}(\sim 2300 \mathrm{~nm}) .^{9,21}$

The IR transmission and absorption cross-section spectra of un-doped and Pr-doped g$\mathrm{Ga}_{2}\left(\mathrm{As}_{0.28} \mathrm{Sb}_{0.12} \mathrm{Se}_{0.60}\right)_{98}$ are presented on Fig. 3. These ChG are seen to possess excellent transparency up to $18 \mu \mathrm{m}$. Owing to higher atomic mass of $\mathrm{Sb}$ in comparison to As, the multiphonon cut-off in $\mathrm{g}-\mathrm{Ga}_{2}\left(\mathrm{As}_{0.28} \mathrm{Sb}_{0.12} \mathrm{Se}_{0.60}\right)_{98}$ is shifted to lower energies in comparison with $\mathrm{g}-\mathrm{Ga}_{2}\left(\mathrm{As}_{0.40} \mathrm{Se}_{0.60}\right)_{98}{ }^{21}$ Similarly to optical transmission in Vis-NIR spectral domain (Fig. 2), RE-doped and undoped ChG show no significant changes in their optical properties. One absorption band of $\operatorname{Pr}^{3+}$ ion is observed in mid-IR region near $4.5 \mu \mathrm{m}$, which can be ascribed to inner-shell electron transitions within $\mathrm{Pr}^{3+}$ ions from ground ${ }^{3} \mathrm{H}_{4}$ to higher ${ }^{3} \mathrm{H}_{5}$ energy level.

The low-temperature (liquid nitrogen $\mathrm{T}=77 \mathrm{~K}$ ) fluorescence spectra of $\mathrm{g}$ $\mathrm{Ga}_{2}\left(\mathrm{As}_{0.28} \mathrm{Sb}_{0.12} \mathrm{Se}_{0.60}\right)_{98}$ doped with 500 wppm of $\operatorname{Pr}^{3+}$ is shown in Fig. 4. The observed broad-band fluorescence emission can be attributed to light absorption in the Urbach edge of host glassy matrix followed by non-radiative energy transfer to RE emitters, as it can be reasonably accepted for these $\mathrm{ChG}$ from previous research. ${ }^{30,31,32}$ The host glass luminescence due to deep states is eventually superimposed with emission originated from radiative transitions between electronic levels of $\operatorname{Pr}^{3+}$ ions. The strongest fluorescence 
emission lines around $1000 \mathrm{~nm}$ on Fig. 4 correspond probably to ${ }^{3} \mathrm{P}_{0^{-}}{ }^{1} \mathrm{G}_{4}$ and ${ }^{1} \mathrm{G}_{4^{-}}{ }^{3} \mathrm{H}_{4}$ transitions, which are most noticeable for these RE ions excited at low temperature. ${ }^{30}$

Thus, in full harmony with above characterization, we nominate the g$\mathrm{Ga}_{2}\left(\mathrm{As}_{0.28} \mathrm{Sb}_{0.12} \mathrm{Se}_{0.60}\right)_{98}$ as quite promising low-phonon energy host capable to successful fiber-optics applications.

\section{(2) PAL response in $R E-$ doping}

Let's trace evolution of atomic-deficient free-volume structure of these ChG responsible for their functionality due to successful RE-doping, exploring the method of annihilating positrons.

The measured PAL spectra of the studied ChG were reconstructed from $\mathrm{x} 2$-term fitting route, these spectra for Ga-codoped $\mathrm{g}_{-} \mathrm{Ga}_{2}\left(\mathrm{As}_{0.28} \mathrm{Sb}_{0.12} \mathrm{Se}_{0.60}\right)_{98}$ and this $\mathrm{ChG}$ doped with 500 wppm of $\operatorname{Pr}^{3+}$ being viewed on Fig. 5. The limited values of statistical scatter of variance tightly grouped along 0 -axis testify that PAL measurements were adequately described within this fitting procedure. So decaying behavior of PAL spectra on Fig. 5 can be reflected by sum of two negative exponentials with different time constants inversed to positron lifetimes. The best-fit positron trapping modes for these $\mathrm{ChG}$ calculated within two-state trapping model ${ }^{13-18}$ are gathered in Table 2 .

The x2-term decomposed PAL spectrum of parent stoichiometric g-As $\mathrm{Se}_{3}$ demonstrates defect-related lifetime $\tau_{2}=0.360 \mathrm{~ns}$ (Table 2), which is proper to this $\mathrm{ChG}$ studied previously. ${ }^{33-36}$. In general, the positron trapping in this $\mathrm{ChG}$ is defined by trapping rate $\kappa_{d}=0.92 \mathrm{~ns}^{-1}$ occurring under fraction of trapped positrons $\eta_{d}=0.19$. In respect to Jensen's et al. DFT-calculations reliably approbated for orthorhombic $\mathrm{As}_{2} \mathrm{Se}_{3}$ structure, ${ }^{35}$ this $\tau_{2}=0.360 \mathrm{~ns}$ lifetime gives an estimate for related volume of positron-trapping sites near $92 \AA^{3}$. This open volume corresponds to $0.10 \mathrm{~ns}$ in $\left(\tau_{2}-\tau_{b}\right)$ difference and 1.39 in $\tau_{2} / \tau_{b}$ ratio, which can be 
accepted as a signature of rather extended triple-quadruple vacancies. Nevertheless, it is difficult to define which part of this overall free volume is really atomic-accessible in glassy network in view of complicated inner structural configuration composed of atom-shared trigonal $\mathrm{AsSe}_{3 / 2}$ pyramids interlinked by $=\mathrm{As}-\mathrm{Se}-\mathrm{As}=$ bridges without essential content of homonuclear As-As and Se-Se bonds (the sketch of typical structural network of $\mathrm{g}-\mathrm{As}_{2} \mathrm{Se}_{3}$ is given in Fig. 6a). ${ }^{5}$ Preferential process of positron trapping in such glassy matrix is defined by extended free-volume spaces near $\mathrm{Se}$ atoms neighboring with $\mathrm{AsSe}_{3 / 2}$ polyhedrons. ${ }^{34,35}$ Because of directionality of covalent bonding in $\mathrm{ChG}$, the $\mathrm{Se}$ atoms form lower-electron density spaces also known as bond free solid angles (BFSA) in terms of Kastner. ${ }^{37}$ These atomic-inaccessible BFSA contribute to neighboring geometrical free volumes, ensuring an effective negative electrical charge due to proximity with electronegative Se atoms linked with more electropositive As or Sb atoms. So, the BFSA around Se atoms form an outer wall for innermost free-volume geometrical voids, which can be identified in view of their preferential electric state as counterparts of cation-type vacancies in crystals. ${ }^{13}$ Therefore, the most efficient positron traps in $\mathrm{g}-\mathrm{As}_{2} \mathrm{Se}_{3}$ can be imaged as free-volume voids formed within cycle-type arrangement of corner-sharing $\mathrm{AsSe}_{3 / 2}$ pyramids, composed of atomic-accessible geometrical holes arrested by surrounding atomic-inaccessible Se-based BFSA. The plane projection of such atomic-deficient structure character for $\mathrm{g}-\mathrm{As}_{2} \mathrm{Se}_{3}$, where A-marked freevolume voids are supposed among others (B- and C-marked) as governing sites for positron trapping is depicted on Fig. 6a.

However, this glassy network with highly saturated covalent bonding does not satisfy condition of electrical charge compensation for RE ions to be embedded in electrically active $\mathrm{RE}^{3+}$ state. This can be achieved for Ga-codoped $\mathrm{ChG}$, i.e. glasses modified by $\mathrm{Ga}$ (alternatively In) additions. ${ }^{6-10}$ 
Effect of Ga-codoping in $\mathrm{g}-\mathrm{As}_{2} \mathrm{Se}_{3}$, i.e. transition from $\mathrm{g}-\mathrm{As}_{2} \mathrm{Se}_{3}$ to $\mathrm{g}-\mathrm{Ga}_{2}\left(\mathrm{As}_{0.40} \mathrm{Se}_{0.60}\right)_{98}$, is revealed through gradual dropping in the $I_{2}$ intensity accompanied by lifting in defectspecific lifetime $\tau_{2}$ to $0.382 \mathrm{~ns}$ (see Table 2). At the basis of Jensen's et al. ${ }^{35}$ formalism, the latter can be ascribed to inner free volumes reaching as high as $\sim 110 \AA^{3}$. This result is in obvious contrast to Ga-modified g-Te ${ }_{20} \mathrm{As}_{30} \mathrm{Se}_{50} \mathrm{ChG}$ (known as TAS-235 glass), ${ }^{24,25}$ where defect-specific positron lifetime $\tau_{2}$ was rather unchanged under Ga-codoping. Such specifics can be reasonably explained by structural changes in a glassy network due to rearrangement in local chemical bonding introduced by incorporated Ga codopants. With Ga codoping in TAS-235 glass, when Ga atoms replace As ones within $\mathrm{Te}_{20}(\mathrm{As} / \mathrm{Ga})_{30} \mathrm{Se}_{50}$ cut-section, the glassy network generally maintains the native average atomic coordination $Z=2.30$, thus ensuring unchanged values of $\tau_{2}$ lifetime regardless Ga content. In the current case of g$\mathrm{Ga}_{2}\left(\mathrm{As}_{0.40} \mathrm{Se}_{0.60}\right)_{98}$, the glassy network enlarges its average atomic coordination from $Z=2.40$ (for $\mathrm{g}-\mathrm{As}_{40} \mathrm{Se}_{60}$ ) to $Z=2.412$. Distinct jump in defect-specific $\tau_{2}$ lifetime is known to occur under such compositional variation in g-As-Se system, ${ }^{16,33,34}$ caused by increased number of overlapped free-volume voids (i.e. BFSA) compactly grouped around end-terminated Se atoms within bridging $\mathrm{Se}_{2 / 2}$-As-As- $\mathrm{Se}_{2 / 2}$ structural units. ${ }^{36}$

Thus, the Ga-codoping in $\mathrm{g}-\mathrm{As}_{2} \mathrm{Se}_{3}$ results in agglomeration of existing free-volume voids (increase in their volume, but decrease in their content), thus leading to gradual decrease in the positron trapping rate in defects $\kappa_{d}$ and, correspondingly, the fraction of trapped positrons $\eta_{d}$ (Table 2).

In general, such compositional modification when only atomic-deficient structure is changed, is meaningless to accommodate $\mathrm{RE}$ ions obeying electrically-active $\mathrm{RE}^{3+}$ state, so avoiding non-radiative decay due to ion-ion interaction, RE-ion clustering and/or glass devitrification. ${ }^{3,8,25,26}$ The nearest atomic environment of free-volume voids accommodated RE dopants have to adopt a local excess of positive electrical charge to ensure compensation 
throughout a glassy matrix. Successful resolution of this problem is just based on the possibility of Ga-codopants to reveal their metallic behavior being inserted in a covalentbonded ChG network. In interaction with chalcogens, the Ga atoms create some polyhedrons, which are, from one side, topologically consistent with principal network-forming polyhedrons to attain unique cycle-type arrangement having a large number of character voids, but, from other side, these codopants are able to stabilize some electrical charge misbalance owing to local chalcogen (Se) over-coordination around Ga atoms. ${ }^{8,10,38}$. Therefore, under transition to $\mathrm{g}-\mathrm{Ga}_{2}\left(\mathrm{As}_{0.40} \mathrm{Se}_{0.60}\right)_{98}$, the $\mathrm{GaSe}_{4 / 2}$ tetrahedrons with energetically favorable Ga-Se bonds appear in a network of corner-shared trigonal $\mathrm{AsSe}_{3 / 2}$ pyramids forming characteristic cycle-atomic arrangement of $\mathrm{g}-\mathrm{As}_{2} \mathrm{Se}_{3}$ (see Fig. 6b). This structure is not disturbed essentially under condition of small amount of Ga codopant added, apart from some homonuclear As-As bonds (red-distinguished on Fig. 6b), which appear to compensate lack of Se atoms in =As-Se-As= bridges. However, excess of these anion-type atoms occupying $\mathrm{Se}^{2-}$ states in cation-centered $\mathrm{GaSe}_{4 / 2}$ tetrahedrons (shown by blue-covered circles on Fig. 6b) causes the cloud of preferentially negative electrical charge for whole neighboring void. In such a way, the negatively-charged void entities of slightly increased volume in Ga-modified ChG serve as precursors for charge-compensating incorporation of electrically active $\mathrm{RE}^{3+}$ ions.

One of expected parasitic drawbacks of Ga-codoping is related to potentially enhanced crystallization ability in Ga-contained $\mathrm{ChG}$ under $\mathrm{RE}$ doping, since both $\mathrm{Ga}$ and $\mathrm{RE}$ chalcogenides possess isostructural crystalline polymorphs. ${ }^{3,21}$ In case of As-based ChG prepared by conventional melt-quenching route, this obstacle can be suppressed under partial As-to-Sb replacement. This was a reason to decline our attention from $\mathrm{g}-\mathrm{Ga}_{2}\left(\mathrm{As}_{0.40} \mathrm{Se}_{0.60}\right)_{98}$ to more vitreous g- $\mathrm{Ga}_{2}\left(\mathrm{As}_{0.28} \mathrm{Sb}_{0.12} \mathrm{Se}_{0.60}\right)_{98}$. In respect to atomic-deficient structure evidenced from PAL spectroscopy, this Sb-substituted ChG demonstrates partial recovery to pure g- 
$\mathrm{As}_{40} \mathrm{Se}_{60}$. Indeed, in this $\mathrm{g}-\mathrm{Ga}_{2}\left(\mathrm{As}_{0.28} \mathrm{Sb}_{0.12} \mathrm{Se}_{0.60}\right)_{98}$, the defect-specific lifetime $\tau_{2}$ is depressed to $0.363 \mathrm{~ns}$ and second component intensity $I_{2}$ is elevated to 0.422 , thus resulting in steadily increasing positron trapping rate in defects with $\kappa_{d}=0.85 \mathrm{~ns}^{-1}$ (see Table 2). This Sbmodification effect is not accompanied by change in the defect type, since neither $\left(\tau_{2}-\tau_{b}\right)$ difference, nor $\tau_{2} / \tau_{b}$ ratio remain constant within measuring error-bar. Such changes are supposed to be defined by increase in the atomic packing of glass-forming network due to heavier $\mathrm{Sb}$ atoms appeared in cation sub-system instead of As atoms, which also cause increase in the atomic density $\rho$ from 4.64 to $4.90 \mathrm{~g} / \mathrm{cm}^{3}$ for $\mathrm{g}-\mathrm{Ga}_{2}\left(\mathrm{As}_{0.40} \mathrm{Se}_{0.60}\right)_{98}$ and g$\mathrm{Ga}_{2}\left(\mathrm{As}_{0.28} \mathrm{Sb}_{0.12} \mathrm{Se}_{0.60}\right)_{98}$, respectively.

Thus, effect of RE-doping on PAL modes can be simply explained in terms of competitive contribution of changed occupancy sites available for RE ions and trapped positrons in the modified structure of Ga-codoped $\mathrm{ChG}$. Indeed, from the point of affinity to negative electrical charge attached to neighboring free-volume space, the same type of voids, which can accommodate $\mathrm{RE}^{3+}$ ions as shown in Fig. 6b, can be also attractive sites for annihilating positrons. ${ }^{13-18}$ Under RE doping, the positively-charged $\operatorname{Pr}^{3+}$ ions are stabilized in a glassy network due to strong $\operatorname{Pr}^{3+}-\mathrm{Se}-\mathrm{Ga}$ covalent bridges, ${ }^{8,39,40}$ thus eliminating corresponding negatively-charged voids (A-marked on Fig. 6) as potential positron traps as it is shown in Fig. 6c. This process results in reduced positron trapping rate in defects $\kappa_{d}$ originated from essential decrease in second component intensity $I_{2}$ (and content of these defects, as it can be expected for such measuring conditions) and rather slight increase in defect-specific lifetime $\tau_{2}$ (Table 2), meaning that void volume is not essentially altered under RE doping.

Concentration of these free-volume defects responsible for positron trapping in RE-doped ChG can be estimated accepting their analogy with negative cation-type vacancies in semiconductors giving trapping coefficients of approximately $10^{15}$ atom $\cdot \mathrm{s}^{-1} \cdot{ }^{13}$ With atomic 
densities (gathered in Table 1) and experimental positron trapping rates for different $\mathrm{ChG}$ (Table 2), this estimation gives defect concentration close to $\sim 5 \cdot 10^{16} \mathrm{~cm}^{-3}$. It means that under a condition of full identity to void occupation for both annihilating positrons and RE-ions, the effect of RE doping can be detected at very low concentration level (reaching only tens of wppm). That is why the PAL spectroscopy can be successfully applied to study RE doping in glassy substances, where conventional atomic-sensitive probes such as X-ray, electron or neutron diffraction are ineffective because of under-margin content of embedded ions, which is typically beyond reliably detectable limits of these methods.

\section{Conclusions}

Free-volume structure of arsenic selenide $\mathrm{As}_{2} \mathrm{Se}_{3}$ glass modified with $\mathrm{Sb}$ (substituting $\mathrm{As}$ ) and codoped with $\mathrm{Ga}$ to $\mathrm{Ga}_{2}\left(\mathrm{As}_{0.28} \mathrm{Sb}_{0.12} \mathrm{Se}_{0.60}\right)_{98}$ composition is traced by annihilating positrons in lifetime measuring mode treated in terms of two-state trapping model. The most efficient positron traps in parent $\mathrm{As}_{2} \mathrm{Se}_{3}$ glass are shown can be imaged as free-volume voids formed within cycle-type arrangement of directly corner-sharing trigonal $\mathrm{AsSe}_{3 / 2}$ pyramids, composed of atomic-accessible geometrical holes arrested by surrounding atomicinaccessible Se-based bond-free solid angles. Positron trapping is mostly depressed in Gacodoped $\mathrm{Ga}_{2}\left(\mathrm{As}_{0.40} \mathrm{Se}_{0.60}\right)_{98}$ glass due to agglomeration of free-volume voids, thus leading to gradual decrease in trapping rate and fraction of trapped positrons. Partial As replacement by heavier $\mathrm{Sb}$ atoms to form $\mathrm{Ga}_{2}\left(\mathrm{As}_{0.28} \mathrm{Sb}_{0.12} \mathrm{Se}_{0.60}\right)_{98}$ glass occurs stabilizing effect on rare-earth doping, partially recovering void structure of parent glass with increased trapping in defects. Effect of 500 wppm of $\operatorname{Pr}^{3+}$ incorporated in $\mathrm{Ga}_{2}\left(\mathrm{As}_{0.28} \mathrm{Sb}_{0.12} \mathrm{Se}_{0.60}\right)_{98}$ glass is explained in terms of competitive contribution of changed occupancy sites available for rare-earth ions and annihilating positrons being trapped in Ga-modified glassy network. Under doping, the $\operatorname{Pr}^{3+}$ ions are stabilized due to $\mathrm{Pr}^{3+}-\mathrm{Se}-\mathrm{Ga}$ linkages, thus eliminating neighboring void as 
potential positron trapping sites. Effect of rare-earth doping in the studied glass results in notably reduced positron trapping rate in free-volume voids, originated from their decreased content and rather slightly altered volume.

\section{Acknowledgements}

With a great pleasure I thank to Roman Golovchak (Austin Peay University, TN, USA) for his helpful assistance with fluorescence measurements. The valuable consulting on PALS experiments provided by Dr. Adam Ingram (Opole University of Technology) is also highly acknowledged. B. Bureau, C. Boussard-Pledel and V. Nazabal (Glass and Ceramics laboratory of University of Rennes 1) are acknowledged for their valuable discussion regarding presented results.

\section{References}

${ }^{1}$ J.-L. Adam, X. Zhang (Eds.), Chalcogenide Glasses: Preparation, Properties and Applications, Woodhead Publishing, Oxford, Cambridge, New Dehli, 2014.

${ }^{2}$ S. Cui, R. Chahal, Ya. Shpotyuk, C. Boussard, J. Lucas, F. Charpentier, H. Tariel, O. Loreal, V. Nazabal, O. Sire, V. Monbet, Z. Yang, P. Lucas, B. Bureau, "Selenide and telluride glasses for mid-infrared bio-sensing," Proc. SPIE, 8938 893805-1-9 (2014).

${ }^{3}$ A.B. Seddon, Z. Tang, D. Furniss, S. Sujecki and T.M. Benson, "Progress in rare-earthdoped mid-infrared fiber lasers," Opt. Express, 18 26704-26719 (2010).

${ }^{4}$ N.F. Mott, E.A. Davis, Electron Processes in Non-Crystalline Materials, Clarendon Press, Oxford, 1979.

${ }^{5}$ A. Feltz, Amorphous and vitreous inorganic solids, Mir, Moscow, 1986.

${ }^{6}$ B. Cole, L.B. Shaw, P.C. Pureza, R. Mossadegh, J.S. Sanghera and I.D. Aggarwal, "Rareearth doped selenide glasses and fibers for active applications in the near and mid-IR," $J$. 
Non-Cryst. Solids, 256-257 253-259 (1999).

${ }^{7}$ J. Hu, C.R. Menyuk, C. Wei, B. Shaw, J.S. Sanghera and I.D. Aggarwal, "Highly efficient cascaded amplification using $\operatorname{Pr}^{3+}$-doped mid-infrared chalcogenide fiber amplifiers," Opt. Lett., 40 3687-3690 (2015).

${ }^{8}$ B.G. Aitken, C.W. Ponader and R.S. Quimby, "Clustering of rare earths in GeAs sulfide glass," C.R. Chimie, 5 865-872 (2002).

${ }^{9}$ M.F. Churbanov, I.V. Scribachev, V.S. Shiryaev, V.G. Plotnichenko, S.V. Smetanin, E.B. Kryukova, Yu.N. Pyrkov and B.I. Galagan, "Chalcogenide glasses doped with Tb, Dy and Pr ions," J. Non-Cryst. Solids, 326-327 301-305 (2013).

${ }^{10}$ R. Golovchak, Ya. Shpotyuk, V. Nazabal, C. Boussard-Pledel, B. Bureau, J. Cebulski, H. Jain, "Study of Ga incorporation in glassy arsenic selenides by high-resolution XPS and EXAFS," J. Chem. Phys., 142 184501-1-10 (2015).

${ }^{11}$ J. Kullmann, D. Enke, S. Thraenert, R. Krause-Rehberg, M. Beiner, "Characterization of pore filling of mesoporous host systems by means of positronium annihilation lifetime spectroscopy (PALS)," Opt. Appl., 42 281-286. (2012).

${ }^{12}$ A.J. Hill, B.D. Freeman, M. Jaffe, T.C. Merkel and I. Pinnau, “Tailoring nanospace,” J. Mol. Struct., 739 173-178 (2005).

${ }^{13}$ R. Krause-Rehberg and H. Leipner, Positron annihilation in semiconductors: defect studies, Springer, Heidelberg, 1999.

${ }^{14}$ Y.C. Jean, P.E. Mallon, D.M. Schrader, Principles and Application of Positron and Positronium Chemistry, World Sci. Publ. Co. Pte. Ltd., New Jersy-London-Singapore-Hong Kong, 2003.

${ }^{15}$ F. Tuomisto and I. Makkonen, "Defect identification in semiconductors with positron annihilation: Experiment and theory," Rev. Mod. Phys., 85 1583-1631 (2013). 
${ }^{16}$ O. Shpotyuk and J. Filipecki, Free volume in vitreous chalcogenide semiconductors: possibilities of positron annihilation lifetime study, WSP, Czestochowa, 2003.

${ }^{17}$ A. Seeger, "The study of defects in crystals by positron annihilation," Appl. Phys., 4 183199 (1974).

${ }^{18}$ D.J. Keeble, U. Brossmann, W. Puff, and R. Würschum, in Characterization of materials, E.N. Kaufmann (Ed.), John Wiley \& Sons, Inc.; New York, 2012, p. 1899-1925.

${ }^{19}$ Ya. Shpotyuk, B. Bureau, C. Boussard-Pledel, V. Nazabal, R. Golovchak, P. Demchenko, I. Polovynko, "Effect of Ga incorporation in the $\mathrm{As}_{30} \mathrm{Se}_{50} \mathrm{Te}_{20}$ glass," J. Non-Cryst. Solids, 398-399 19-25 (2014).

${ }^{20}$ O. Shpotyuk, A. Ingram, B. Bureau, Ya. Shpotyuk, C. Boussard-Pledel, V. Nazabal, R. Szatanik, "Positron annihilation probing of crystallization effects in TAS-235 glass affected by Ga additions," J. Phys. Chem. Solids, 75 1049-1053 (2014).

${ }^{21}$ Ya. Shpotyuk, C. Boussard-Pledel, V. Nazabal, R. Chahal, J. Ari, B. Pavlyk, J. Cebulski, J.L. Doualan, B. Bureau, "Ga-modified $\mathrm{As}_{2} \mathrm{Se}_{3}-\mathrm{Te}$ glasses for active applications in IR photonics," Opt. Mater., 46 228-232 (2015).

${ }^{22}$ A. Hrubý, "Evaluation of glass-forming tendency by means of DTA," Czech. J. Phys. B, 22 1187-1193 (1972).

${ }^{23}$ J. Kansy, "Microcomputer program for analysis of positron annihilation lifetime spectra," Nucl. Instrum. Methods Phys. Res., Sect. A, 374 235-244 (1996).

${ }^{24}$ Ya. Shpotyuk, A. Ingram, O. Shpotyuk, A. Dziedzic, C. Boussard-Pledel, B. Bureau, "Freevolume nanostructurization in Ga-modified $\mathrm{As}_{2} \mathrm{Se}_{3}$ glass," Nanoscale Res. Lett., 11 20-1-7 (2016).

${ }^{25}$ Ya. Shpotyuk, A. Ingram, O. Shpotyuk, C. Boussard-Pledel, V. Nazabal, B. Bureau, "Effect of rare-earth doping on the free-volume structure of Ga-modified $\mathrm{Te}_{20} \mathrm{As}_{30} \mathrm{Se}_{50}$ glass," $R S C$ $A d v ., 622797-22802$ (2016). 
${ }^{26}$ Ya. Shpotyuk, A. Ingram and O. Shpotyuk, "PAL spectroscopy of rare-earth doped Ga-GeTe/Se glasses. Journal of Physics and Chemistry of Solids," J. Phys. Chem. Solids, 91 76-79 (2016).

${ }^{27}$ Ya. Shpotyuk, C. Boussard-Pledel, V. Nazabal, B. Bureau, "The influence of Sb on glass forming ability of Ga-containing $\mathrm{As}_{2} \mathrm{Se}_{3}$ glasses," J. Am. Ceram. Soc., DOI: 10.1111/jace.14662.

${ }^{28}$ E. Cernoskova, J. Holubova, B. Bureau, C. Roiland, V. Nazabal, R. Todorov, Z. Cernosek, “Thermoanalytical properties and structure of $\left(\mathrm{As}_{2} \mathrm{Se}_{3}\right)_{100-\mathrm{x}}\left(\mathrm{Sb}_{2} \mathrm{Se}_{3}\right)_{\mathrm{x}}$ glasses by Raman and ${ }^{77}$ Se MAS NMR using a multivariate curve resolution approach," J. Non-Cryst. Solids, 432 426-431 (2016).

${ }^{29}$ J. Musgraves, N. Carlie, L. Petit, K. Richardson, G. Boudebs, J. Choi, M. Richardson, "Effect of replacement of As by $\mathrm{Ge}$ and $\mathrm{Sb}$ on the photo-response under near infrared femtosecond laser irradiation in As-based sulfide glasses," Intern. J. Appl. Glass Sci., 2 308$320(2011)$.

${ }^{30}$ J. Zavadil, P. Kostka, J. Pedlikova, Z.G. Ivanova, K. Zdansky, "Investigation of Ge based chalcogenide glasses doped with Er, Pr and Ho," J. Non-Cryst. Solids, 356 2355-2359 (2010). ${ }^{31}$ S.Q. Gu, S. Ramachandran, E.E. Reuter, D.A. Turnbull, J.T. Verdeyen, S.G. Bishop, "Photoluminescence and excitation spectroscopy of Er-doped $\mathrm{As}_{2} \mathrm{~S}_{3}$ glass: Novel broad band excitation mechanism,” J. Appl. Phys., 77 3365-3371 (1995).

${ }^{32}$ S.G. Bishop, D.A. Turnbull, B.G. Aitken, "Excitation of rare earth emission in chalcogenide glasses by broadband Urbach edge absorption," J. Non-Cryst. Solids, 266-269 876-883 (2000).

${ }^{33}$ O.K. Alekseeva, V.I. Mihailov, A.P. Chernov, V.P. Shantarovich, "Point structural defects studied in chalcogenide semiconductors by positron annihilation," Sov. Fiz. Tverd. Tela, 19 3452-3454 (1977). 
${ }^{34}$ O.K. Alekseeva, V.I. Mihajlov, V.P. Shantarovich, "Positron annihilation in point defects of the glassy As-Se system," Phys. Stat. Solidi A, 48 K169-K173 (1978).

${ }^{35}$ K.O. Jensen, P.S. Salmon, I.T. Penfold, P.G. Coleman, "Microvoids in chalcogenide glasses studied by positron annihilation,” J. Non-Cryst. Solids, 170 57-64 (1994).

${ }^{36}$ A. Ingram, R. Golovchak, M. Kostrzewa, S. Wacke, M. Shpotyuk, O. Shpotyuk, "Compositional dependences of average positron lifetime in binary As-S/Se glasses," Phys. $B, 407$ 652-655 (2012).

${ }^{37}$ M. Kastner, "Compositional trends in the optical properties of amorphous lone-pair semiconductors," Phys. Rev. B, 7 5237-5252 (1973).

${ }^{38}$ R. Golovchak, Ya. Shpotyuk, C.M. Thomas, V. Nazabal, C. Boussard-Pledel, B. Bureau, H. Jain. "Peculiarities of Ga and Te incorporation in glassy arsenic selenides," J. Non-Cryst. Solids, 429 104-111 (2015).

${ }^{39}$ T.H. Lee, S.I. Simdyankin, L. Su and S.R. Elliott, "Evidence of formation of tightly bound rare-earth clusters in chalcogenide glasses and their evolution with glass composition," Phys. Rev. B, 79 180202-1-4 (2009).

${ }^{40}$ T.H. Lee, S.I. Simdyankin, J. Hegedus, J. Heo, S.R. Elliott, "Spatial distribution of rareearth ions and $\mathrm{GaS}_{4}$ tetrahedra in chalcogenide glasses studied via laser spectroscopy and ab initio molecular dynamics simulation," Phys. Rev. B, 81 104204-1-6 (2010).

\section{Figures caption list:}

Fig. 1. Two-state positron trapping model with a single free-volume vacancy.

Fig. 2. Vis-NIR transmission and absorption cross section spectra of $\mathrm{Ga}_{2}\left(\mathrm{As}_{0.28} \mathrm{Sb}_{0.12} \mathrm{Se}_{0.60}\right)_{98}$ and $\mathrm{Ga}_{2}\left(\mathrm{As}_{0.28} \mathrm{Sb}_{0.12} \mathrm{Se}_{0.60}\right)_{98}+500$ wppm of Pr samples.

Fig. 3. IR transmission and absorption cross section spectra of $\mathrm{Ga}_{2}\left(\mathrm{As}_{0.28} \mathrm{Sb}_{0.12} \mathrm{Se}_{0.60}\right)_{98}$ and $\mathrm{Ga}_{2}\left(\mathrm{As}_{0.28} \mathrm{Sb}_{0.12} \mathrm{Se}_{0.60}\right)_{98}+500$ wppm of Pr samples.

Fig. 4. Low-temperature fluorescence spectra of $\mathrm{Ga}_{2}\left(\mathrm{As}_{0.28} \mathrm{Sb}_{0.12} \mathrm{Se}_{0.60}\right)_{98}$ doped with 500 wppm of $\operatorname{Pr}^{3+}$. Intensity of fluorescence (a.u.) is given by color map at the right. Straight 
(grey) lines are caused by Rayleigh scattering of the excitation light (ignored during analysis).

Fig. 5. Raw PAL spectra of Ga-codoped $\mathrm{Ga}_{2}\left(\mathrm{As}_{0.28} \mathrm{Sb}_{0.12} \mathrm{Se}_{0.60}\right)_{98}$ (a) and $\mathrm{Ga}_{2}\left(\mathrm{As}_{0.28} \mathrm{Sb}_{0.12} \mathrm{Se}_{0.60}\right)_{98}$ doped with 500 wppm of $\operatorname{Pr}^{3+}$ (b). The bottom insets show statistical scatter of variance.

Fig. 6. Sketch of plane projection of atomic-deficient void structure of g-(As/Sb $)_{2} \mathrm{Se}_{3}$ built of corner-sharing $(\mathrm{As} / \mathrm{Sb}) \mathrm{Se}_{3 / 2}$ pyramids showing character cycle-type arrangement with freevolume voids in Ga-free (a), Ga-codoped (b) and RE-modified Ga-codoped (c) glass-forming network (see text for more details).

Table 1. Input characterization of $\mathrm{g}-\mathrm{Ga}_{\mathrm{x}}\left[(\mathrm{As} / \mathrm{Sb})_{0.40} \mathrm{Se}_{0.60}\right]_{100-x}$

\begin{tabular}{|c|c|c|c|c|c|c|}
\hline \multirow{2}{*}{ ChG composition } & \multirow{2}{*}{$Z$} & $\rho$ & $V_{m}$ & $T g$ & $T x$ & $\Delta T$ \\
\hline & & $\mathrm{g} / \mathrm{cm}^{3}$ & $\mathrm{~cm}^{3} / \mathrm{mol}$ & ${ }^{\circ} \mathrm{C}$ & ${ }^{\circ} \mathrm{C}$ & ${ }^{\circ} \mathrm{C}$ \\
\hline g- $\mathrm{As}_{40} \mathrm{Se}_{60}$ & 2.400 & 4.619 & 16.74 & 184 & --- & --- \\
\hline $\mathrm{g}-\mathrm{Ga}_{2}\left(\mathrm{As}_{0.40} \mathrm{Se}_{0.60}\right)_{98}$ & 2.412 & 4.635 & 16.66 & 182 & 307 & 125 \\
\hline $\mathrm{g}-\mathrm{Ga}_{2}\left(\mathrm{As}_{0.28} \mathrm{Sb}_{0.12} \mathrm{Se}_{0.60}\right)_{98}$ & 2.412 & 4.900 & 16.88 & 191 & $\begin{array}{ll}-- \\
-\end{array}$ & $\begin{array}{ll}-- \\
\end{array}$ \\
\hline $\begin{array}{l}\text { g-Ga }\left(\mathrm{As}_{0.28} \mathrm{Sb}_{0.12} \mathrm{Se}_{0.60}\right)_{98} \\
\text { with } 500 \text { wppm } \mathrm{Pr}^{3+}\end{array}$ & 2.412 & 4.890 & 16.95 & 195 & 307 & 112 \\
\hline
\end{tabular}

Table 2. Fitting parameters and positron trapping modes describing two-component reconstructed PAL spectra in g- $\mathrm{Ga}_{\mathrm{x}}\left[(\mathrm{As} / \mathrm{Sb})_{0.40} \mathrm{Se}_{0.60}\right]_{100-x}$

\begin{tabular}{|c|c|c|c|c|c|c|c|c|c|}
\hline \multirow{3}{*}{ ChG sample } & \multicolumn{3}{|c|}{ Fitting parameters } & \multicolumn{6}{|c|}{ Positron trapping modes } \\
\hline & $\tau_{1}$ & $\tau_{2}$ & $I_{2}$ & $\tau_{a v}$ & $\tau_{b}$ & $\kappa_{d}$ & $\tau_{2}-\tau_{b}$ & $\tau_{2} / \tau_{b}$ & $\eta_{d}$ \\
\hline & ns & ns & a.u. & ns & ns & $n s^{-1}$ & ns & - & - \\
\hline $\mathrm{g}-\mathrm{As}_{40} \mathrm{Se}_{60}$ & 0.210 & 0.360 & 0.462 & 0.279 & 0.260 & 0.92 & 0.10 & 1.39 & 0.19 \\
\hline $\mathrm{g}-\mathrm{Ga}_{2}\left(\mathrm{As}_{0.40} \mathrm{Se}_{0.60}\right)_{98}$ & 0.223 & 0.382 & 0.401 & 0.287 & 0.267 & 0.75 & 0.11 & 1.43 & 0.17 \\
\hline $\mathrm{g}-\mathrm{Ga}_{2}\left(\mathrm{As}_{0.28} \mathrm{Sb}_{0.12} \mathrm{Se}_{0.60}\right)_{98}$ & 0.210 & 0.363 & 0.422 & 0.274 & 0.255 & 0.85 & 0.11 & 1.42 & 0.18 \\
\hline $\begin{array}{l}\mathrm{g}-\mathrm{Ga}_{2}\left(\mathrm{As}_{0.28} \mathrm{Sb}_{0.12} \mathrm{Se}_{0.60}\right)_{98} \\
\text { with } 500 \text { wppm of } \mathrm{Pr}^{3+}\end{array}$ & 0.218 & 0.374 & 0.376 & 0.276 & 0.258 & 0.72 & 0.12 & 1.45 & 0.16 \\
\hline
\end{tabular}



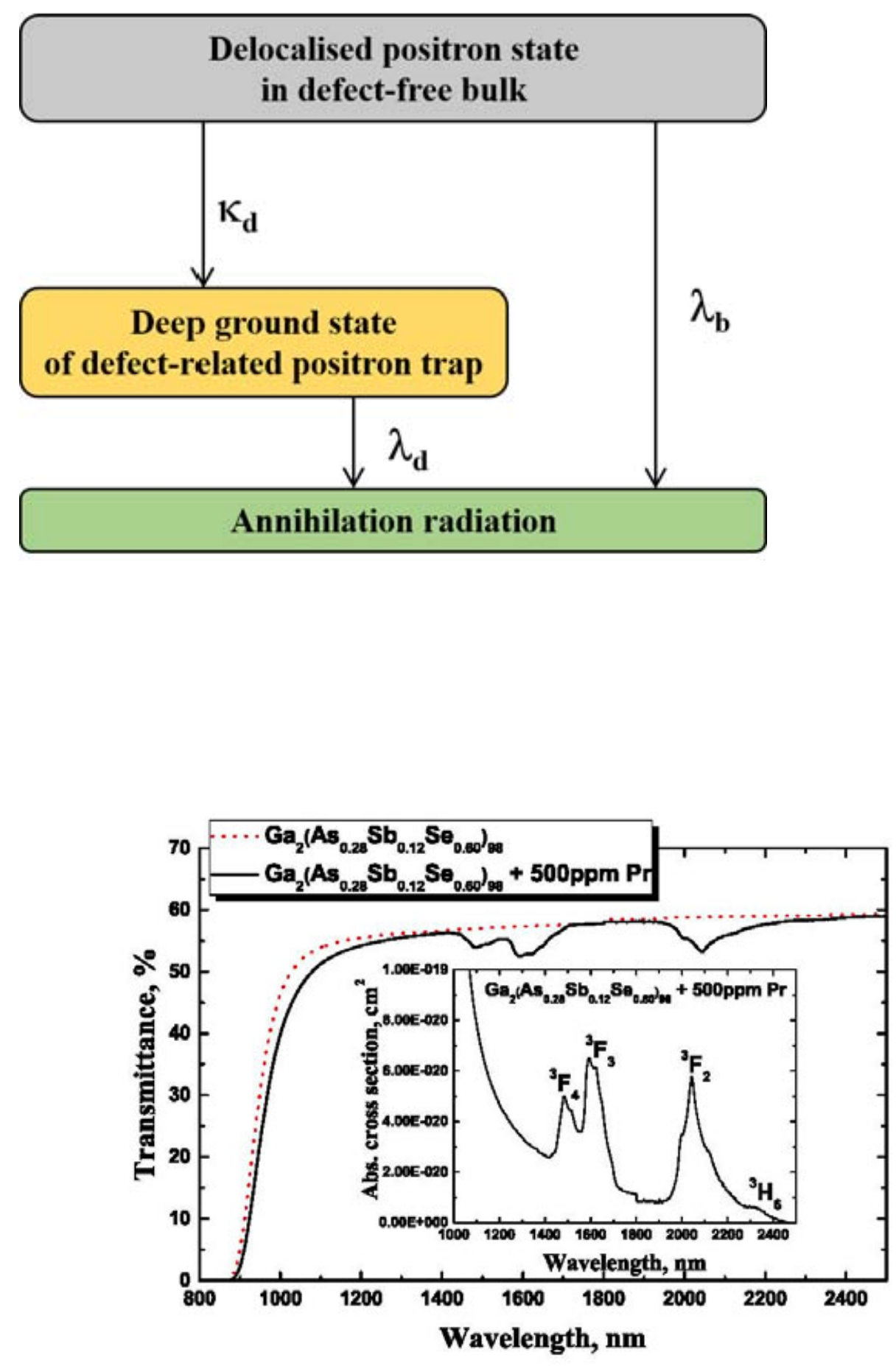

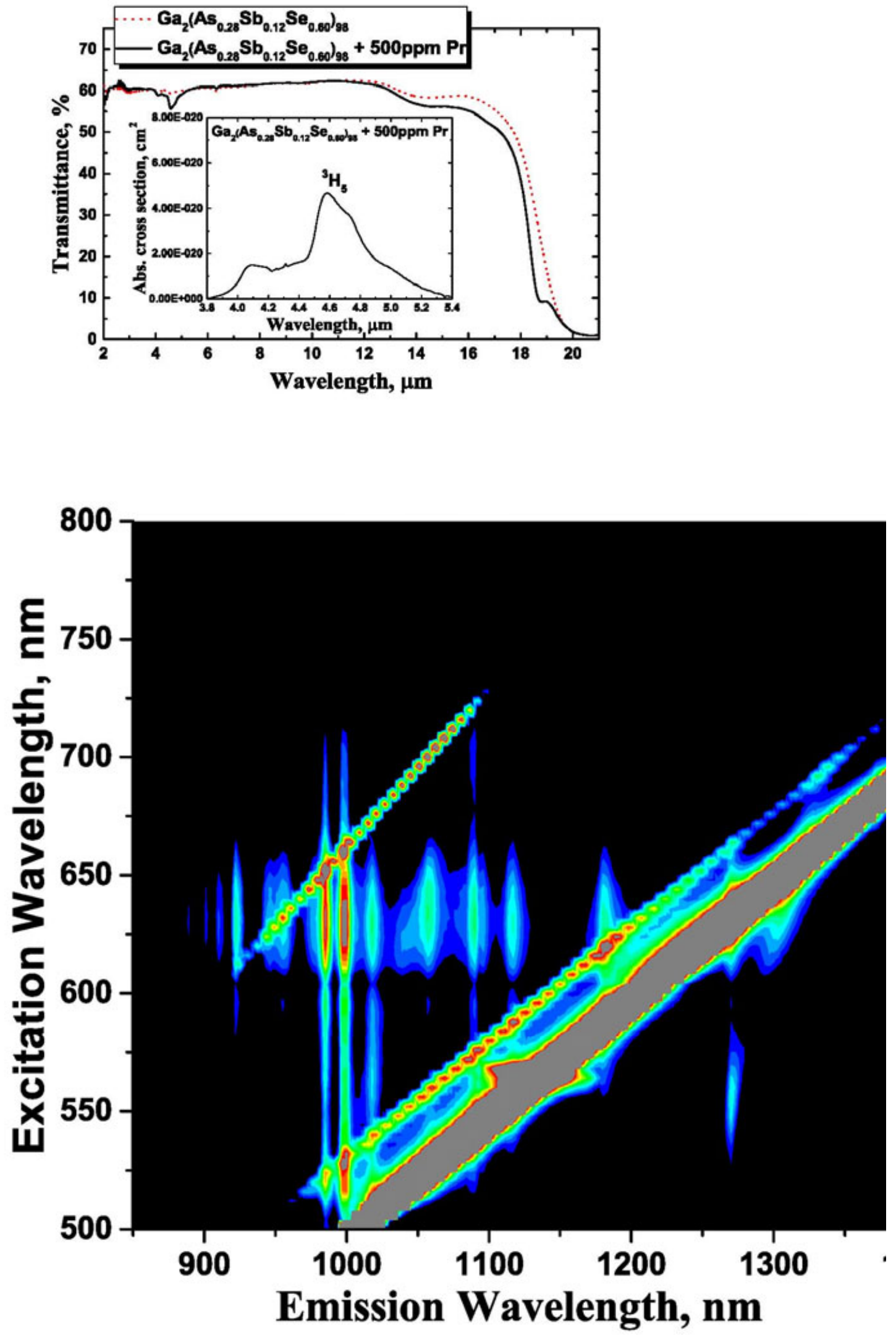

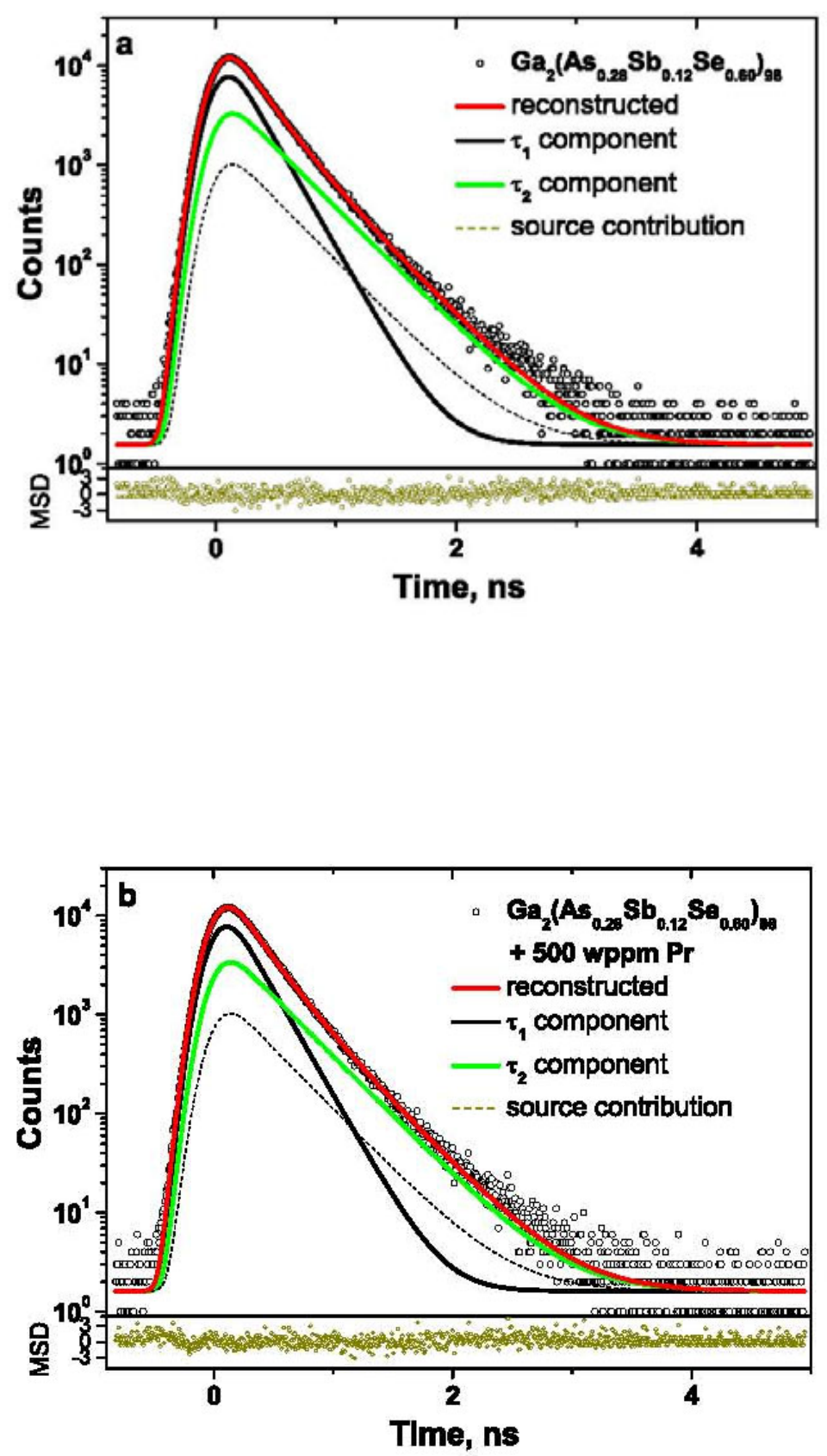

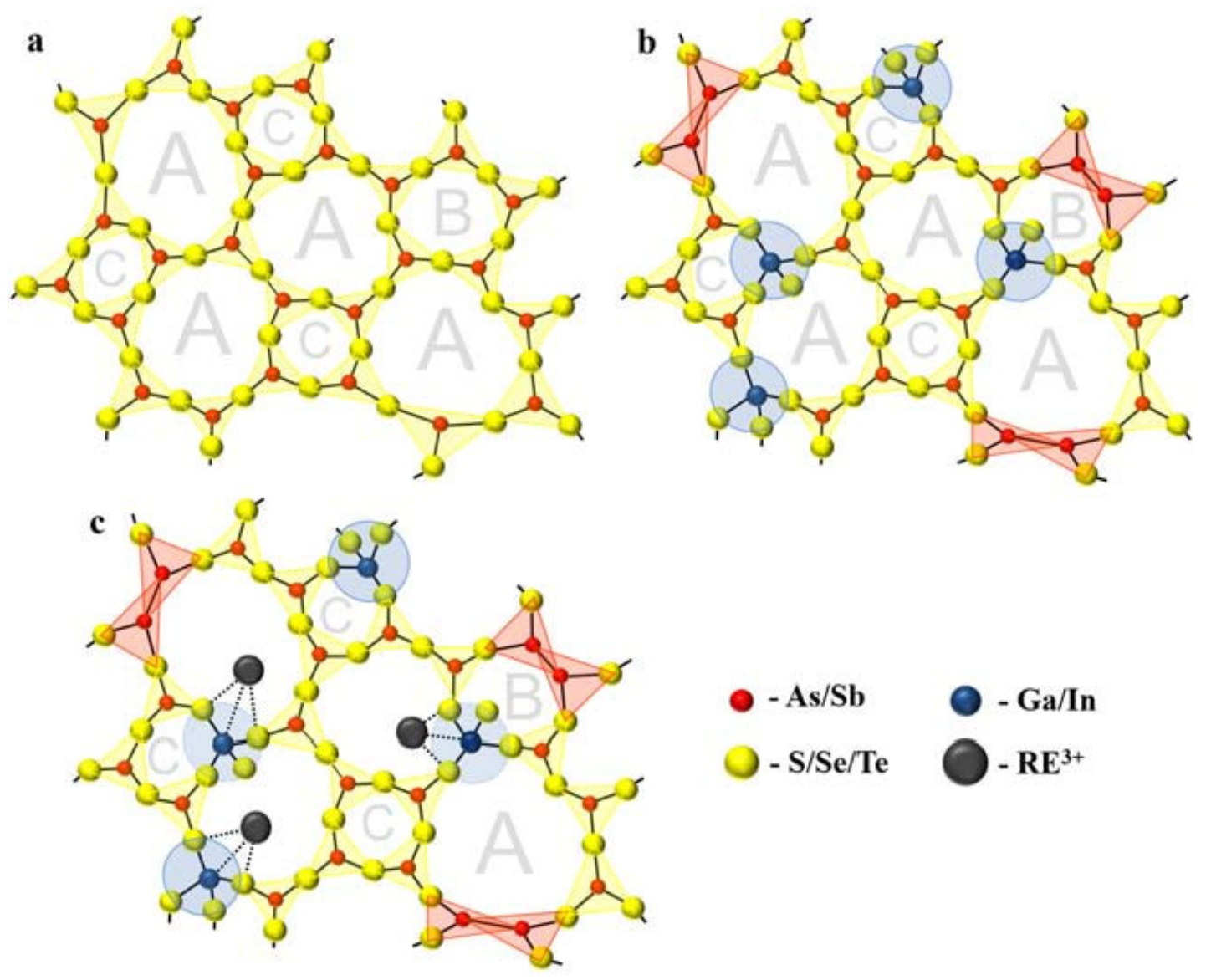